\title{
Human reliability analysis - accounting for human actions and external factors through the project life cycle
}

\author{
C. Morais
}

Institute for Risk and Uncertainty, University of Liverpool, UK

National Agency for Petroleum, Natural Gas and Biofuels (ANP), Brazil

R. Moura

National Agency for Petroleum, Natural Gas and Biofuels (ANP), Brazil

Institute for Risk and Uncertainty, University of Liverpool, UK

\author{
M. Beer \\ Institute for Risk and Reliability, Leibniz Universitat Hannover, Germany \\ Institute for Risk and Uncertainty, University of Liverpool, UK \\ E. Patelli \\ Institute for Risk and Uncertainty, University of Liverpool, UK
}

School of Civil Engineering and Shanghai Institute of Disaster Prevention and Relief, Tongji University, China

\begin{abstract}
Airplanes, ships, nuclear power plants and chemical production plants (including oil \& gas facilities) are examples of industries that depend upon the interaction between operators and machines. Consequently, to assess the risks of those systems, not only the reliability of the technological components has to be accounted for, but also the 'human model'. For this reason, engineers have been working together with psychologists and sociologists to understand cognitive functions and how the organisational context influences individual actions.

Human Reliability Analysis (HRA) identifies and analyses the causes, consequences and contributions of human performance (including failures) in complex sociotechnical systems. Generally, HRA research is concentrated in modelling workers' performance in the "sharp-end", assessing the ones directly involved in handling the system, especially operators. However, in theory, a reliability analysis can be applied to any kind of human action, including those from designers and managers.

This research will evaluate a way of conducting HRA in the design process, as previous research has demonstrated that design failure is the predominant contributor to human errors (Moura et al., 2016).

Bayesian Network (BN) - a systematic way of learning from experience and incorporating new evidence (deterministic or probabilistic) - is proposed to model the complex relationships within cognitive functions, organisational and technological factors. Conditional probability tables have been obtained from a dataset of major accidents from different industry sectors (Moura et al. 2017), using a classification scheme developed by Hollnagel (1998) for an HRA method called CREAM - Cognitive Reliability and Error Analysis Method.
\end{abstract}

The model allows to infer which factors most influence human performance in different scenarios. Also, we will discuss if the model can be applied to any human actions through the project life cyclesince the design phase to the operational phase, including their management.

\section{INTRODUCTION}

\subsection{Human Reliability Analysis (HRA)}

Human reliability analysis can have three objectives: identify human performance (as failures and their consequences), quantify the likelihood of failure (and error recovery) and to reduce or remediate those errors in the system (Kirwan, 1997).
The expected results of such study can be either qualitative or quantitative, depending on the industry sector best practice, data availability and regulatory requirements.

Quantitative results for HRA means giving the human performance a number, a probability of occurrence - the so-called Human Error Probability (HEP). This gives decision-makers the 
opportunity to decrease the HEP to as low as practicable by tackling the factors that impact it, or to check if a certain risk criteria is met.

HRA research, practice and regulatory requirements are currently focused on operation and maintenance workers-called 'sharp-end' workers - those who actually interact with the processes (Reason, 1990; Hollnagel, 1998).

\subsection{HRA in design phase}

Can human reliability analysis be applied in other phases of an industrial project, such as design, construction, commissioning and decommissioning?

Theoretically speaking, it is possible: where there is human action, there is the possibility to model, analyse and measure performance (Hollnagel, 1998).

This research will focus on the design phase and design changes during other phases, as there is evidence from previous studies that design failure is the organisational factor that most triggers human failure actions (Moura et al., 2016).

One of the constraints of this approach is that human (engineers and managers) performance in the design stage has limited public data, preventing detailed task analyses.

However, it is also known that design failures identified in latter stages of the lifecycle (i.e. operational phase) are much more expensive to correct, compared to those detected during the design stage (Kohler and Moffatt, 2003).

Thus, it is believed that understanding engineers and managers performance during the design phase would have the potential to motivate improvements in organisational design procedures, based on overall accident patterns.

It is a trade-off between having perfect data but not sufficient resources to make design changes in the operational phase and having imperfect data but sufficient resources to improve the design in earlier stages of the lifecycle.

\subsection{Can human performance influence design?}

Design failure is often considered an organisational factor in HRAs, as the methods and assessors take into account that it influences human performance and not the opposite.

In contrast, there are studies, outside the safety and engineering community, showing that organisations are not an unmanned box of procedures, but individuals deciding whether using them, based on other factors like regulations, knowledge and resources (Rocha Fernandes et al., 2005). Besides, those individuals, usually middle and front-line managers, have a significant influence in all levels of the organisation, dictating and implementing the organisational strategy (Wooldridge et al., 2008; Purcell, 2007).

Another key aspect of this discussion is recognising the difference between 'managing the design' and 'managing design changes'. First, because they can occur in different phases of a project and thus managed by completely different team profiles.

Second, because decision-making in engineering practice can have two distinct meanings: 'design decisions' are the ones about the design itself (e.g. which equipment to choose in a system), while 'management decisions' are the ones about the team responsible for designing the system or issues that impact this team (Herrmann, 2015).

Each of these different concepts leads to a different kind of performance to analyse.

\section{METHODOLOGY}

\subsection{Classification scheme used}

The classification scheme is considered the collection of error modes (cognitive functions and human actions) and the Performance Shaping Factors (PSFs) which shapes the context that triggers each error mode.

To achieve the aim of this research, it is essential to use an HRA classification scheme that recognises cognitive functions, as both 'design decisions' and 'management decisions' cannot be evidenced only by actions described in most classification schemes from the first generation of HRAs.

For this reason, a classification scheme of the second generation of HRA was chosen (see Hollnagel, 1998, to understand the differences between the first and the second HRA generation).

From the publicly available ones, there are only two methods from the second generation that are considered useful to the Major Hazard Directorates of HSE, the UK safety regulator (Bell and Holroyd, 2009): CREAM (Hollnagel, 1998) and ATHEANA (Forester et al., 2007).

From these two choices, CREAM's (i.e. the Cognitive Reliability and Error Analysis Method) classification scheme was chosen to conduct this research, as it shows a clear distinction between causes and manifestations. This enables the application of the method in both directions: to analyse major accidents retrospectively and to predict events as a traditional HRA method. Therefore, this feature made it possible to use a pre-existent dataset from major industrial accidents (Moura et al., 2016) in the current work, as explained in the next section.

This classification scheme splits cognitive functions into two categories: analysis (the mental processes used when someone tries to understand a problem) and synthesis (the mental processes used 
Table 1. Summary of errors of cognition used in CREAM.

\begin{tabular}{|c|c|c|}
\hline Analysis & Observation & $\begin{array}{l}\text { Observation missed } \\
\text { False observation } \\
\text { Wrong identification }\end{array}$ \\
\hline & Interpretation & $\begin{array}{l}\text { Faulty diagnosis } \\
\text { Wrong reasoning } \\
\text { Decision error } \\
\text { Delayed interpretation } \\
\text { Incorrect prediction }\end{array}$ \\
\hline Synthesis & Planning & $\begin{array}{l}\text { Inadequate plan } \\
\text { Priority error }\end{array}$ \\
\hline
\end{tabular}

to solve the problem). Further, these are also split into subcategories, as summarized in Table 1.

One of the problems that may be argued against this choice is that most HRA performed in practice are the ones from the first generation (Zwirglmaier et al., 2015, Henderson and Embrey, 2012), such as THERP, HEART and SPAR-H. Also, according to CREAM's creator, all the PSFs presented at the classification scheme are still useful, apart from the cognitive reliability, that he considers a 'misleading oversimplification' (Hollnagel, 2012). According to him, "explaining human performance as based on 'cognitive processes' represents a myopic information processing view, and talking about the reliability of such processes is an artefact of the PRA/ PSA mindset".

However, the current research is not using CREAM as an HRA method, limiting the discussion to the assessment of the HEPs, as a way to disclose possible improvements.

\subsection{Data used}

To generate Human Error Probabilities (HEP), or to validate HRA methods, different types of data are used. Kirwan (1997) classified them as: (i) real or operationally derived data (i.e. from incidents and near misses), (ii) simulator derived data, (iii) data from the psychological and ergonomics performance literature, (iv) expert judgement, (v) other techniques.

Data from real operation are considered the one with highest quality, but also the more difficult to obtain. That is because to achieve an absolute result for the HEP (number of observed errors by the number of opportunities for error) both the numerator and denominator of the equation should be assessed by the observation of each human action through an industry lifecycle. This is impractical, as one should count even the actions and errors that have not led to incidents.

For this reason, much research is being conducted using operationally derived data as near misses (i.e. events with the potential for undesirable consequences (CCPS, 2007) and accidents occurred in industrial installations.

Preischl and Hellmich (2013) used data from near misses, occurred on German nuclear power plants, to construct their model to estimate HEPs, in order to check validation of THERP handbook estimates. Groth and Mosleh (2012) have used the HERA database, from retrospective analyses of risk-significant events occurred on nuclear power plants, that contain at least one human error.

In the current research, it was decided to use a dataset derived from major accidents from different industrial sectors, not yet tested as model to estimate HEPs: the MATA-D - Multi-attribute Technological Accidents Dataset, built by Moura et al. (2016).

Differently from near misses reports, investigation reports of major accidents have the potential to uncover more PSFs that trigger a human error. This is because major accidents' investigations usually use several man-hours of an expert team (Moura et al. 2016)aiming to achieve an increased depth of analysis, eventually reaching root causes such as organizational issues (CCPS, 2007).

MATA-D has been derived from the analysis of 238 accident reports from different industrial sectors using the same classification scheme, with the intention to optimise the learning from cross-sector accidents. All the reports had evidence on the presence of organisational, technological and person-related factors, the PSFs described in Table 3. Also, nearly half of all the reports had indications about the cognitive functions and actions executed, described in Tables 1 and 2.

The MATA-D dataset is a table of 238 accidents by fifty-three parameters (thirty-nine factors, ten cognitive functions and four erroneous actions), where the number one represents the presence of a parameter in an accident report and the zero its absence.

For the reasons listed above, it has been decided to use the available MATA-D data to feed a model, in order to understand if the results could describe human performance in design and its management, instead of modelling the whole process, developing PSFs, collecting data and creating a new method from scratch.

\subsection{Modelling method used — Bayesian network}

The relationships between PSFs, cognitive functions and human erroneous actions described

Table 2. Erroneous actions used in the classification scheme.

Errors of execution

Wrong time Wrong type Wrong place Wrong object 
Table 3. PSFs from CREAM classification scheme.

\begin{tabular}{|c|c|c|}
\hline $\begin{array}{l}\text { Organisational } \\
\text { factors }\end{array}$ & $\begin{array}{l}\text { Technological } \\
\text { factors }\end{array}$ & $\begin{array}{l}\text { Person related } \\
\text { factors }\end{array}$ \\
\hline $\begin{array}{l}\text { Communication } \\
\text { failure }\end{array}$ & $\begin{array}{l}\text { Equipment } \\
\text { failure }\end{array}$ & $\begin{array}{l}\text { Memory failure } \\
\text { Fear }\end{array}$ \\
\hline Missing information & Software fault & Distraction \\
\hline Maintenance failure & $\begin{array}{l}\text { Inadequate } \\
\text { procedure }\end{array}$ & $\begin{array}{l}\text { Fatigue } \\
\text { Performance }\end{array}$ \\
\hline $\begin{array}{l}\text { Inadequate quality } \\
\text { control }\end{array}$ & $\begin{array}{l}\text { Access } \\
\text { limitations }\end{array}$ & $\begin{array}{l}\text { Variability } \\
\text { Inattention }\end{array}$ \\
\hline $\begin{array}{l}\text { Management } \\
\text { problem }\end{array}$ & $\begin{array}{l}\text { Ambiguous } \\
\text { information }\end{array}$ & $\begin{array}{l}\text { Physiological } \\
\text { stress }\end{array}$ \\
\hline Design failure & $\begin{array}{l}\text { Incomplete } \\
\text { information }\end{array}$ & $\begin{array}{l}\text { Psychological } \\
\text { stress }\end{array}$ \\
\hline $\begin{array}{l}\text { Inadequate task } \\
\text { allocation }\end{array}$ & $\begin{array}{l}\text { Access } \\
\text { problems }\end{array}$ & $\begin{array}{l}\text { Functional } \\
\text { impairment }\end{array}$ \\
\hline Social pressure & Mislabelling & Cognitive style \\
\hline Insufficient skills & & Cognitive bias \\
\hline $\begin{array}{l}\text { Insufficient } \\
\quad \text { knowledge }\end{array}$ & & \\
\hline Temperature & & \\
\hline Sound & & \\
\hline Humidity & & \\
\hline Illumination & & \\
\hline Other & & \\
\hline $\begin{array}{l}\text { Adverse ambient } \\
\text { conditions }\end{array}$ & & \\
\hline Excessive demand & & \\
\hline $\begin{array}{l}\text { Inadequate workplace } \\
\text { layout }\end{array}$ & & \\
\hline $\begin{array}{l}\text { Inadequate team } \\
\text { support }\end{array}$ & & \\
\hline $\begin{array}{l}\text { Irregular working } \\
\quad \text { hours }\end{array}$ & & \\
\hline
\end{tabular}

above were modelled into a Bayesian network (BN). BN is known as a systematic way of learning from experience and to incorporate new evidence (deterministic or probabilistic), and it was chosen due to the possibility of modelling those complex relationships within variables of different nature.

Mkrtchyan et al. (2015) had suggested that using $\mathrm{BN}$, human reliability analysis also benefits from:

i. Its graphical formalism (Figure 1) of conditional probability equations (Equation 1). Using the visual representation of $\mathrm{BN}$ is a practical way of discussing the relations between factors, facilitating the communication between the multidisciplinary team that should be involved in an HRA meeting analysis, such as engineers, psychologists and sociologists.

$\mathrm{P}(\mathrm{C}=\mathrm{c} 1 \mid \mathrm{A}=\mathrm{a} 1, \mathrm{~B}=\mathrm{b} 1) \mathrm{P}(\mathrm{C}=\mathrm{c} 2 \mid \mathrm{A}=\mathrm{a} 1, \mathrm{~B}=\mathrm{b} 1)=$ $1-\mathrm{P}(\mathrm{C}=\mathrm{c} 1 \mid \mathrm{A}=\mathrm{a} 1, \mathrm{~B}=\mathrm{b} 1)$ ii. A probabilistic representation of uncertainty, making it compatible with Probabilistic Safety Assessment.

iii. Combination of different sources of information: empirical sources as databases of events, theoretical models of human cognition and expert judgement.

The mathematical background of Bayesian networks was described by Tolo et al. (2014) as statistical models used to represent probability distributions, that can provide combined probability distribution associated to an accident, exploiting information about the existing conditional dependencies, e.g. between PSFs and cognitive functions.

$\mathrm{BNs}$ are represented by acyclic graphs, where nodes are connected to each other by arcs (Figure 1). Child nodes must have a causality relationship with each parent node.

For example, consider in Figure 2, the child node 'cognitive function'. The probability of its occurrence is conditioned to the occurrence of its parent nodes: organisation, technology and

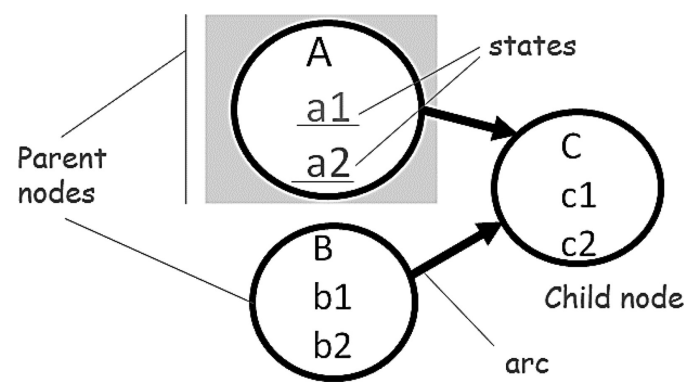

Figure 1. Directed acyclic graphs typical of a Bayesian network.

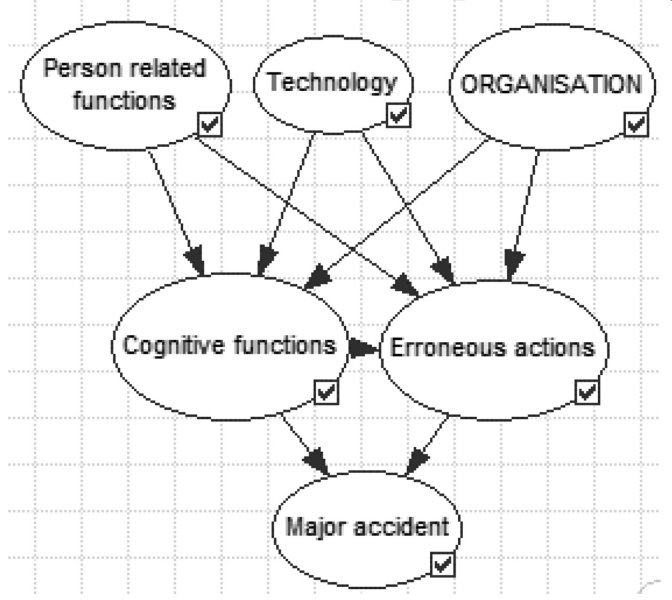

Figure 2. Example of a Bayesian network. 
person-related functions. To have a proper causality, one has to know the answer to the question: what is the probability of occurring a cognitive function when the organisation, technology or person related factors occur altogether? What about when none of them occurs? And if only an organisational factor occurs, and no technology and person-related factor? All possible eight combinations from three parent nodes have to be answered, to establish a proper causality.

Generically speaking, the number of combinations a conditional probability table has to represent a child node is two (pair of combinations) to the power of the number of parent nodes $\left(2^{\wedge}\right.$ parent nodes).

This means a high number of combinations if all the factors of the CREAM methodology are considered. The implications of this issue are discussed in the next section.

\section{MODEL}

\subsection{Bayesian model of human reliability}

To build and test the human reliability model, it was used the summarised process represented by Figure 3. It was proposed by Mkrtchyan et al. (2015), through their review of HRA methods using BN models.

First, the nodes and their states were defined. Then, the structure, which means the links between the nodes. After the structure, comes the assessment of Conditional Probability Tables (CPT) for each node. Finally, a verification was conducted. The validation process will be conducted in a future work.

\subsection{Nodes and states}

The nodes used in the model are the sub-factors of CREAM classification scheme (Hollnagel, 1998), where the major factors are human, technology and organisation.

The states of the nodes will be 'presence' or 'absence' of the sub-factors observed during the investigation of major accidents.

The result of the MATA-D dataset, presented in the methodology section of this paper, has fed our model as a matrix of zeros and ones of 53 rows $\times 238$ columns. At the dataset, the absence of a parameter (factor, cognitive function or action) is

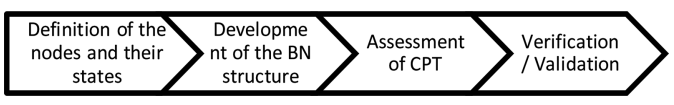

Figure 3. Process to build a BN model to HRA. represented by the number zero and the presence of them in an accident represented by the number one.

Only the factors, cognitive functions and actions in italic in Tables 1 and 2 were used as nodes for the model. The reason is explained in the next section.

\subsection{Structure}

Basically, to create the structure of this BN model, parent nodes (organisational, technological and person-related factors) were linked by arrows to the child nodes (cognitive functions and human erroneous actions).

It would be that simple if there were no limitations from the algorithm used to build the model in Genie software. For the reason explained in section 2.2, the thirty-nine factors provided by the classification scheme would generate $549,755,813,888$ combinations (two to the power of thirty-nine) more that was supported by the BN software used.

The algorithm supports a large number of nodes, but not a large number of connections to one child node. Therefore, it was necessary to make assumptions to simplify the model structure.

To make assumptions about connections between nodes, one must have a clear understanding of the causal relationship that factors transmit to cognitive functions.

That is the reason why the most common way to simplify a model, for human reliability purpose, is using expert judgement, also known as expert elicitation (Mkrtchyan et al. 2015). However, it is also the stage where happens one of the most claimed disadvantages of using Bayesian networks for human reliability analysis: it is argued that experts can bring more uncertainties to a model due to their personal bias.

In an attempt to avoid this kind of uncertainty, the strategy was to let the data 'speak' for itself. This strategy has been already used by Groth and Mosleh's (2012) at their BN model, where they had introduced nodes of 'error context' to align certain combinations of PIFs that are more likely to produce human errors than the individual PSFs acting alone.

At the present work, the 'error context' was represented as the arcs of the $\mathrm{BN}$ model instead of the nodes. The context was imported from the treatment applied by Moura et al. (2017) to their dataset, to disclose common patterns and significant features among major accidents. They have used an artificial neural network approach to the dataset, a data mining process that translated the information into a graphical interface, the self-organising maps (SOM). Analysing them, one can perceive that the 238 accidents are allocated into four different regions, shaped by the clustering of accidents with a similar profile and, thus, a similar combination of factors, cognitive functions and actions. 
Summing up, the model connections were proposed based on those SOM relations: factors that were in the cluster \#1 were linked only to cognitive functions located on the same cluster, and the same process was repeated for all the clusters.

Simplifications to the network structure were applied not only to the connections but also to the number of nodes. Using previous research by Moura et al. (2017), the nodes were restricted to the factors, cognitive functions and actions considered significant for the dataset of major accidents by the self-organising maps algorithm.

Consequently, if a factor had represented negative or very low variations in the formation of one of the SOM clusters, it was interpreted that that factor was not significant to the causation pattern of major accidents and, consequently, it was not included in the Bayesian model presented in this paper. The considered nodes are presented in italic in Tables 1, 2 and 3, and in the nodes represented in Figure 4.

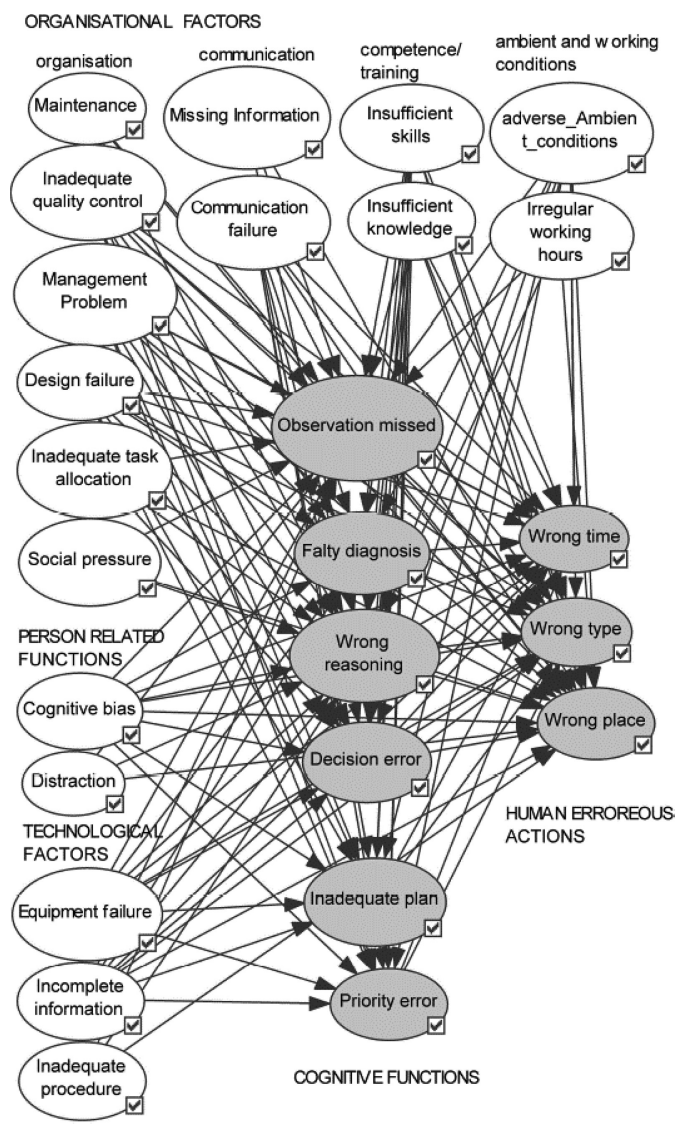

Figure 4. Bayesian model considered.
The model considers that cognitive functions are affected by each factor and that human erroneous actions are affected by the factors and by the cognitive functions. That is because the model assumes that workers have a mental process behind their actions (Hollnagel, 1998).

\subsection{Conditional Probability Tables (CPT)}

Conditional probability tables have been obtained from the dataset of major accidents from different industry sectors (Moura et al. 2017), using the CREAM classification scheme (Hollnagel, 1998).

After the simplification on the network, the higher number of combinations to a child node reached was the node 'wrong place', with nineteen parent nodes combinations, considering the possibility of occurring a 'wrong place action' influenced by sixteen factors and three cognitive functions. That means 524,288 combinations, and thus 524,288 probabilities of an action to occur or not.

The prior probabilities of the model were obtained by calculating how many times a specific combination occurred, divided by the total number of accidents of the dataset.

\subsection{Software used}

The accident dataset developed by Moura et al. (2016) has been originally built as a table of zeros and ones, that was uploaded to the $\mathrm{BN}$ software.

If the number of combinations was small, an Excel spreadsheet could be used to find the CPT and export to GeNIe software. However, as presented in the previous section, the dataset generated conditional probability tables of 524,288 probabilities for some child nodes. This row (or vector) of data extrapolates Excel software limits, and thus Matlab had to be used. Also, to optimise the data gathering, it was necessary some coding skills to create the Conditional Probability Tables - as 'filtering' the combinations in Excel would consume too much time.

The BN model was built in GeNIe Modeler for academic use (BayesFusion, LLC). The clustering algorithm embedded in the software was used to calculate the posterior probabilities, and the node type used was 'chance-general'.

Useful explanations of how to use the GeNIe software can be found in the manual provided by the developer and also by the authors of an evacuation time analysis of ships using BN (Sarshar et al., 2013).

\section{RESULTS}

After building the model, inserting the prior probabilities of parent and child nodes (through their 
Table 4. Marginal probabilities of human performance.

\begin{tabular}{llll}
\hline Cognitive functions & \multicolumn{3}{l}{ Actions } \\
\hline Observation & & Wrong time & $4.21 \mathrm{e}-04$ \\
Observation missed & $8.12 \mathrm{e}-05$ & Wrong type & $1.73 \mathrm{e}-04$ \\
Interpretation & & Wrong place & $4.64 \mathrm{e}-04$ \\
Faulty diagnosis & $1.05 \mathrm{e}-03$ & & \\
Wrong reasoning & $1.05 \mathrm{e}-03$ & & \\
Decision error & $6.35 \mathrm{e}-04$ & \\
Planning & & \\
Inadequate plan & $1.22 \mathrm{e}-03$ & \\
Priority error & $6.50 \mathrm{e}-04$ & \\
\hline
\end{tabular}

conditional probability tables), the marginal probability distributions were calculated using Genie software, as presented in Table 4:

Although a validation was not yet conducted, the order of magnitude of the HEPs (cognitive functions and erroneous actions) is consistent with HRA directives from the Oil \& Gas industry (OGP, 2010), and HRA documents obtained at the website of the Environmental Protection Department of The Government of the Hong Kong (2017). A validation is needed to understand if the model is optimistic or pessimistic, according to validation criteria discribed by Kirwan (1997).

\subsection{Verification step}

To verify if the model behaves according to its specifications, some scenarios were created, changing the factors to its extremes. It means that each parent node was assumed to be 0 and 1 separately. In other words, each factor (organisational, personal and technological) was assumed to be absent or present in an industrial scenario.

To achieve that, after changing the factors, the posterior probabilities of the human performance nodes were calculated, updating the Bayesian network.

\subsection{Sensibility of human performance to each factor}

To infer which factors most influence human performance, the results from the verification process have been used.

When a factor node was set as present in a scenario (state 1 of the node), it was assumed that the variation caused to the posterior probability of a human performance node is the sensibility of this parameter to that change. Note that the parameters are represented by small probabilities, so changes in their marginal probability are also expected to be small. Thus, for better visualisation of the sensibility, the variation in percentage has been calculated.
As can be noticed in Table 5, there is a slight increase in the presence of missed observations when Inadequate Quality Control and Design Failure, both organizational factors, are present in a scenario. Moderated positive variation is also perceived when the technological factors equipment failure and inadequate procedure are present. Interpretation functions (faulty diagnosis, wrong reasoning and decision error) are the most influenced parameters by changes in organisational and technological factors.

Errors in design and equipment failures also increase errors in interpretation functions (mainly in wrong reasoning), but the results show a more accentuated positive variation at interpretation when changes of quality control, task allocation and knowledge (related to training) occurs.

While interpretation has its presence affected by training (knowledge), planning incidence seems to be more related to experience (skills).

Failures in equipment increase the possibility of poor planning in an accident scenario, but not as much as the inadequate quality control and design failure, both organisational factors.

Errors of execution (wrong time, type and place) are triggered by quality control, design failure, task allocation and, with fewer effect, equipment failure.

The results suggest that some factors do not make cognitive functions vary positively, possibly meaning that an error on cognitive functions would not occur with a scenario with errors in factors as maintenance, management, social pressure and irregular working hours.

\section{CONCLUSION AND DISCUSSIONS}

The Bayesian model proposed was built to serve as a tool to predict human performance in industrial scenarios, i.e. the human failure probability, with the potential to be applied in different sectors such as chemical (including oil \& gas processing), nuclear and aviation.

The novelty of the present model is the use of a dataset of major accidents to define the basic aspects of a Bayesian network HRA model: nodes, states, structure and prior probabilities (conditional probability table). The model was developed as one of the objectives to achieve the aim of understanding human performance in the design phase.

Some discussions are developed below in the form of answers to questions proposed for this research.

\subsection{Can this model be used for HRA purposes?}

Not yet. All the steps of the model were executed, apart from the validation. The intention is to 


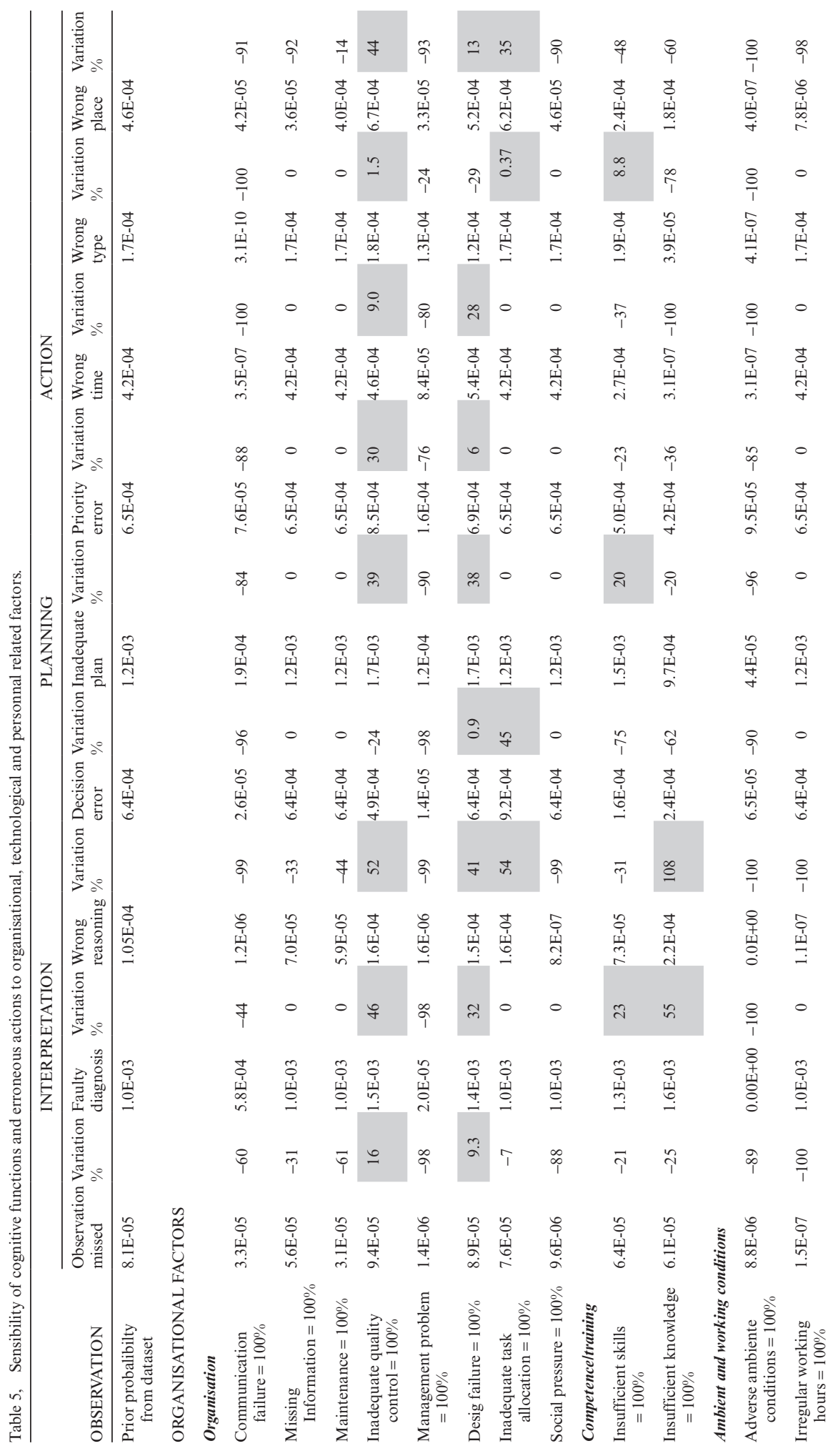




\begin{tabular}{|c|c|c|c|c|}
\hline 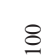 & 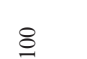 & $\overline{0}$ & \pm & $\stackrel{\infty}{\sim}$ \\
\hline 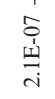 & $\begin{array}{l}\hat{1} \\
\hat{o} \\
\text { j్ } \\
\text { b }\end{array}$ & $\begin{array}{l}\text { ț } \\
\text { ț } \\
\text { ț } \\
+\end{array}$ & 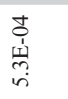 & 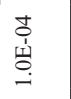 \\
\hline$\overline{\hat{\imath}}$ & 0 & $\underset{\infty}{+}$ & 0 & $\stackrel{\circ}{\circ}$ \\
\hline $\begin{array}{l}n \\
o \\
\text { ț } \\
\text { to } \\
\text { - }\end{array}$ & 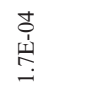 & $\begin{array}{l}n \\
o \\
\text { i⿱ } \\
\infty \\
i\end{array}$ & 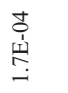 & 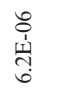 \\
\hline$\stackrel{8}{1}$ & 0 & $\stackrel{ナ}{+}$ & & $\stackrel{+}{\vec{n}}$ \\
\hline $\begin{array}{l}\stackrel{7}{1} \\
\stackrel{4}{\infty} \\
\stackrel{i}{i}\end{array}$ & 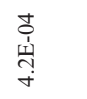 & $\begin{array}{l}\stackrel{+}{S} \\
\text { I } \\
\stackrel{+}{+}\end{array}$ & $\begin{array}{l}\text { 吉 } \\
\text { गे } \\
\text { I }\end{array}$ & $\begin{array}{l}\text { ț } \\
\text { I্ } \\
\text { ì } \\
\text { in }\end{array}$ \\
\hline aे & 0 & t & 0 & ô \\
\hline $\begin{array}{l}\stackrel{0}{0} \\
\text { I1 } \\
\infty \\
\text { r. }\end{array}$ & 草 & 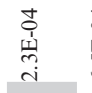 & 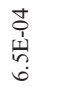 & 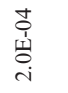 \\
\hline$\frac{8}{1}$ & 0 & $\cong$ & 0 & \& \\
\hline $\begin{array}{l}\stackrel{8}{0} \\
\text { 11 } \\
\infty \\
i \\
i n\end{array}$ & 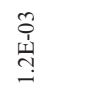 & $\begin{array}{l}\stackrel{\wp}{\hat{i}} \\
\stackrel{+}{+} \\
\stackrel{+}{-}\end{array}$ & 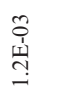 & 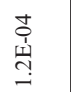 \\
\hline a & o & $\stackrel{\infty}{i}$ & 0 & $\stackrel{\infty}{\uparrow}$ \\
\hline 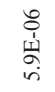 & $\begin{array}{l}\text { 草 } \\
\text { 岌 } \\
\text { b }\end{array}$ & 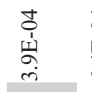 & $\begin{array}{l}\text { 草 } \\
\text { I. } \\
\text { f. }\end{array}$ & $\begin{array}{l}\stackrel{+}{0} \\
\text { 岌 } \\
\stackrel{-}{-}\end{array}$ \\
\hline $\begin{array}{c}\infty \\
\substack{1 \\
1}\end{array}$ & 8 & g & $\hat{i}$ & $\overline{\hat{i}}$ \\
\hline 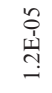 & 产 & $\begin{array}{l}\underset{+}{0} \\
\text { ț } \\
\stackrel{1}{0} \\
-\end{array}$ & 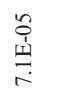 & 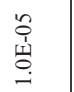 \\
\hline$\stackrel{1}{1}$ & 0 & $\uparrow$ & 0 & - \\
\hline 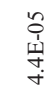 & 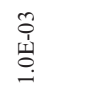 & 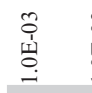 & 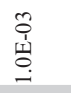 & 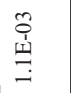 \\
\hline$\tilde{\phi}^{\infty}$ & ta & $=$ & $=$ & Fै \\
\hline 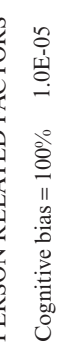 & 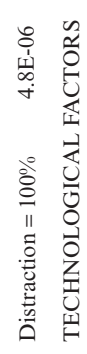 & 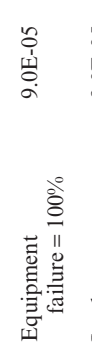 & 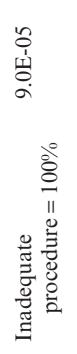 & 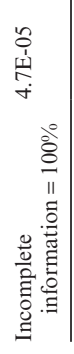 \\
\hline
\end{tabular}

validate the model against data from recent major accident that are not yet covered by the original dataset, to measure if the model describes other real operational data.

In future works, the dataset can be adapted to PSFs of classification schemes from other HRA methods.

\subsection{Is the model able to describe human actions through all the project life cycle?}

Although the verification step suggests the model is capable of inferring which factors most influence human performance, the model still interprets design as a PSF affecting human performance in other stages - and do not consider PSFs affecting designers. In addition, it is believed that some factors may influence design phase in a different way from the prior probability extracted from the dataset of major accidents

Although it is believed that this model cannot describe the design phase, it has the potential to describe changes in design during the operational phase. In fact, that is one of the uncertainties that need to be investigated in the dataset used, as some situations described as a design failure can be attributed to changes in the initial design during latter phases. This can also change part of the prior probabilities considered in this model.

Further development must consider the creation of new PSFs, with new organisational factors that should be considered during design. It seems that expert elicitation will have to be considered phaseas there is few public evidence of this process.

\subsection{Can this model be used to understand decision-makers performance during design?}

The model has the potential to describe frontline and middle managers' routine and emergency performance, during the operational phase. It is expected that it will give a better description of cognitive functions than actions, as a reflection of the decision-makers typical job description.

However, further investigation should be conducted to understand how specific factors affect different people in the organisation, specially for organisational factors for which results suggested that the impact in cognitive function is marginal, such as social pressure and irregular working hours. These factors, for instance, are reported in the literature (Thomas et al., 1999) to affect middle-managers in a different way, compared to sharp-end employees.

The importance of understanding managers' safety performance is part of the present research, as a way of investigating if improving their performance on safety issues has the potential to lead 
industries to better organisational factors and fewer accidents. Managers are linked at the same time to top management and operational teamshaving the opportunity to sell new ideas to top management and to promote strategic change to employees (Wooldridge et al., 2008; Purcell, 2007).

For this reason, it is recommended that further models consider all factors proposed by CREAM's classification scheme, instead of only using the significant ones according to previous research (Moura et al., 2017). Accounting for factors like 'excessive demand' and 'cognitive style' might give an improved model for managers' roles. With this purpose, different software and algorithms to calculate posterior probabilities have to be tested, to support more links between nodes. Therefore, Cossan (Patelli et al., 2018), a software for Uncertainty Quantification and its Bayesian network toolbox will be tested in the future.

\section{REFERENCES}

BayesFusion, LLC. GeNIe Modeler. http://www.bayesfusion.com/, Accessed: 30 November 2017.

Bell, J. and Holroyd, J., 2009. Review of human reliability assessment methods. Health and Safety Laboratory.

Center for chemical Process Safety - CCPS, Guidelines for Risk Based Process Safety. 2007.

Environmental Protection Department of The Government of the Hong Kong, Project file submitted for application for Environmental Impact Assessment. Chapter of Human Error Assessment \& Reduction Technique. http://www.epd.gov. hk/eia/register/ report/eiareport/eia_2242014/EIA/app/app12.10.pdf (Accessed: 11 December 2017).

Forester, J., Kolaczkowski, A., Cooper, S., Bley, D. and Lois, E., 2007. ATHEANA user's guide. NUREG1880, NRC.

Groth, K.M. and Mosleh, A., 2012. Deriving causal Bayesian networks from human reliability analysis data: A methodology and example model. Proceedings of the Institution of Mechanical Engineers, Part O: Journal of Risk and Reliability,226(4), pp.361-379.

Henderson, J. and Embrey, D., 2012. Quantifying human reliability in risk assessments. Petroleum review, 66(790).

Herrmann, J., 2015. Engineering Decision Making and Risk Management. New Jersey: John Wiley \& Sons, Inc.

Hollnagel, E., 1998. Cognitive reliability and error analysis method (CREAM). Elsevier.

Hollnagel, 2016. Disclaimer about CREAM. http:// erikhollnagel.com/ideas/cream.html (Accessed: 13 December 2017).

International Association of Oil \& Gas Producers (IOGP), 2010. Human factors in QRA. Risk Assessment Data Directory, Report No. 434-5.
Kirwan, B., 1997. Validation of human reliability assessment techniques: part 1 -validation issues. Safety Science, 27(1), pp.25-41.

Mkrtchyan, L., Podofillini, L. and Dang, V.N., 2015. Bayesian belief networks for human reliability analysis: A review of applications and gaps. Reliability engineering \& system safety, 139, pp.1-16.

Moura, R.; Beer, M.; Patelli, E.; Lewis, J. \& Knoll, F. Learning from past accidents to improve system design Safety Science, 2016, 84, 37-45

Moura, R.; Beer, M.; Patelli, E. \& Lewis, J. Learning from major accidents: graphical representation and analysis of multi-attribute events to enhance risk communication Learning from Incidents Special Issue of the Safety Science Journal, 2017

Kohler, N. and Moffatt, S., 2003. Life-cycle analysis of the built environment. Industry and environment, 26(2-3), pp.17-21.

Patelli, E.; Tolo, S.; George-Williams, H.; Sadeghi, J.; Rocchetta, R.; Angelis, M.D. \& Broggi, M. OpenCossan 2.0: an efficient computational toolbox for risk, reliability and resilience analysis Proceedings of the joint ICVRAM ISUMA UNCERTAINTIES conference, 2018 (submitted)

Preischl, W. and Hellmich, M., 2013. Human error probabilities from operational experience of German nuclear power plants. Reliability Engineering \& System Safety, 109, pp.150-159.

Purcell, J. and Hutchinson, S., 2007. Front-line managers as agents in the HRM-performance causal chain: theory, analysis and evidence. Human Resource management journal, 17(1), pp.3-20.

Reason, J., 1990. Human Error. Cambridge University Press, Cambridge.

Rocha Fernandes, B.H., Mills, J.F. and Tereza L. Fleury, M., 2005. Resources that drive performance: an empirical investigation. International Journal of Productivity and Performance Management, 54(5/6), pp.340-354.

Sarshar, P., Granmo, O.C., Radianti, J. and Gonzalez, J.J., 2013, April. A Bayesian network model for evacuation time analysis during a ship fire. In Computational Intelligence in Dynamic and Uncertain Environments (CIDUE), 2013 IEEE Symposium on (pp. 100-107). IEEE.

Thomas, R. and Dunkerley, D., 1999. Careering downwards? Middle managers' experiences in the downsized organization. British Journal of Management, 10(2), pp.157-169.

Tolo, S.; Patelli, E. \& Beer, M. Bayesian Network Approach for Risk Assessment of a Spent Nuclear Fuel Pond Vulnerability, Uncertainty, and Risk, American Society of Civil Engineers, 2014, 598-607

Wooldridge, B., Schmid, T. and Floyd, S.W., 2008. The middle management perspective on strategy process: Contributions, synthesis, and future research. Journal of management, 34(6), pp.1190-1221.

Zwirglmaier, K., Straub, D. and Groth, K.M., 2015. Framework for a Bayesian Network Version of IDHEAS. Safety and Reliability of Complex Engineered Systems: ESREL 2015, Taylor \& Francis Group, London, pp. 3165-3172. 